\title{
Herpes zoster infection presenting as neurogenic bladder dysfunction
}

\author{
Ebru Erden, Gökhan Tuna Öztürk, Murat Ersöz \\ Department of Physical Medicine and Rehabilitation, Ankara Physical Medicine and Rehabilitation Training and Research Hospital, Ankara, Turkey \\ Received: September 2016 Accepted: October 2016
}

Herpes zoster infection is a disease characterized by maculopapular rash and dermatomal or neuropathic pain limited to one side of body. ${ }^{[1]}$ Rarely, bladder dysfunction with acute urinary retention is seen due to the involvement of sacral dermatomes. ${ }^{[2]}$ Herein, we present a case of an uncommon symptom of herpes zoster infection presenting as bladder dysfunction with globe vesicale due to affected sacral dermatomes. Herpes zoster infection should be kept in mind as one of the causes of neurogenic bladder dysfunction.

Dear editor, a 65-year-old female patient with stroke was admitted to our clinic for post-stroke rehabilitation. During follow-up, complex regional pain syndrome developed on her hemiplegic side, and she received corticosteroid treatment (methylprednisolone $24 \mathrm{mg} /$ day was initiated and reduced by $4 \mathrm{mg}$ every 5 days). During the treatment process, dermatomal pain, maculopapular rash, and difficulty in urination (globe vesicale) developed (Figure 1). The patient was diagnosed with herpes zoster infection (zona) and her symptoms alleviated following valacyclovir treatment $(3,000 \mathrm{mg} /$ day $)$. Herpes zoster infection is a disease characterized by maculopapular rash and dermatomal or neuropathic pain limited to one side of body. ${ }^{[1]}$ Rarely, bladder dysfunction with acute urinary retention is seen due to involvement of sacral dermatomes. ${ }^{[2]}$ Our case had an uncommon symptom of herpes zoster infection presenting as bladder dysfunction with globe vesicale due to affected sacral dermatomes. Herpes zoster infection should be kept in mind as one of the causes of neurogenic bladder dysfunction.

\section{Declaration of conflicting interests}

The authors declared no conflicts of interest with respect to the authorship and/or publication of this article.

\section{Funding}

The authors received no financial support for the research and/or authorship of this article.

\section{REFERENCES}

1. Bölük H, Karabay İ, Öztürk GT, Tunç H, Ersöz M. Herpes zoster infection manifesting with sciatalgia. Turk J Phys Med Rehab 2015;61:293-4.

2. Tsai HN, Wu WJ, Huang SP, Su CM, Chen CC, Wang CJ, et al. Herpes zoster induced neuropathic bladder--a case report. Kaohsiung J Med Sci 2002;18:39-44. 